\title{
COMPARATIVE STUDY BETWEEN SINGLE ANASTOMOSIS SLEEVE ILEAL BYPASS AND MINIGASTRIC BYPASS AND THEIR EFFECT ON HAEMOGLOBIN, ALBUMIN, CALCIUM AND FOLATE
}

\section{Alaa Abbaas Moustafa, Tamer Mohamed Said, Mohamed Gamal Alfouly and Mostafa Saad Abdelsalam *}

\author{
General Surgery Department, \\ Faculty of Medicine, Ain Shams \\ University \\ Corresponding Author: \\ Mostafa Saad Abdelsalam \\ Phone No.: (+2) 01001442344 \\ E-mail: \\ dr.mostafasaad100@gmail.com \\ Received: $1 / 4 / 2020$ \\ Accepted: 29/4/2020
}

Online ISSN: 2735-3540

\section{ABSTRACT}

Background: Bariatric surgery has been shown to be the most successful approach in managing morbid obesity that can achieve and sustain great weight loss for a long period. Such surgeries, which adopt restrictive, malabsorptive, or mixed procedures, have shown to achieve good and promising results in weight loss. However, such procedures necessitate lifelong medical supervision with the supplementation of vitamins and nutrients. Moreover, these are frequently associated with dysphagia and vomiting as a result of anatomical restrictions, and can lead to serious metabolic disorders.

Aim of The Work: To compare preliminary outcomes between single anastmosis sleeve ileal bypass and mini-gastric bypass at one year, as regards to their effects on hemoglobin, albumin, calcium and Folate.

Patients and Methods: This is A prospective comparative study was conducted in Eldmerdash Hospital and El Sahel Teaching Hospital including 60 patients who will undergo bariatric surgery. Patients will be divided into two groups: either (group I) or (group II). The two groups had the same indications for surgery.

Results: A significant BMI reduction was observed in both groups at 1, 6 and 12 months of the follow-up. The mean BMI values were significantly lower in the group 1 compared to group 2 during the whole follow-up, but the differences in $\%$ EWL were not significant. At 1,6 and 12 months postoperatively, there was no significant difference between groups in haemoglobin, albumin, calcium and folic acid levels.

Conclusion: The preoperative nutritional status is indicative for the incidence and time of onset of post-operative deficiencies which can contribute to optimal nutritional follow-up. Standard supplementation decreases the incidence of post-operative deficiencies.

Keywords: Minigastric Bypass, Single Anastomosis

\section{INTRODUCTION:}

Bariatric surgery has been shown to be the most successful approach in managing morbid obesity that can achieve and sustain great weight loss for a long period. Such surgeries, which adopt restrictive, malabsorptive, or mixed procedures, have shown to achieve good and promising results in weight loss ${ }^{(1-2)}$.

However, such procedures necessitate lifelong medical supervision with the supplementation of 
vitamins and nutrients. Moreover, these are frequently associated with dysphagia and vomiting as a result of anatomical restrictions, and can lead to serious metabolic disorders ${ }^{(3)}$.

Bariatric surgery improves quality of life and comorbid conditions and decreases overall cost of care. Patients that undergo surgery will likely increase the length of their lives due to improvement in diabetes and heart disease and decreased risk of cancer. Long-term bariatric follow-up requires a team approach and attention to several aspects of care. Nutrition is the most important aspect of follow-up to safely maximize weight loss and prevent weight gain. Exercise helps to maintain weight loss. Complications need to be identified early and can result from improper behaviour or from surgical complications ${ }^{(4)}$.

Nutritional derangements due to deficiencies of micronutrients like iron, vitamin B12, fat soluble vitamins, thiamine, and folate are especially common after malabsorptive bariatric procedures. Studies in which prophylactic iron or vitamin B12 was administered lost significance in the odds ratio for postoperative vitamin B12 deficiency. Postoperative prophylactic iron and B12 supplementation, in addition to general multivitamin and mineral supplementation, is recommended based on the comparable deficiency risk of the 2 methods as indicated by subgroup analysis ${ }^{(5)}$.

Bariatric surgery has gained in popularity for treatment of morbid obesity in USA and all around the world. Despite laparoscopic gastric bypass (LRYGB) was found as the gold standard procedure at the beginning of the 21 st century, laparoscopic single anastomosis sleeve ileal bypass (SASI) and laparoscopic mini gastric bypass (LMGB) are procedures challenging LRYGB since few years. This is partly because both procedures have been found to be faster, easier and have similar or better weight loss compared to LRYGB with better postoperative profiles $^{(6)}$.

MGB is safe, results in major weight loss, has a short operating-time, and has a short hospital stay. The MGB appears to meet many of the criteria of an "ideal" weight loss operation ${ }^{(7)}$.
Performance of MGB with a $200 \mathrm{~cm}$ bypassed limb in a morbidly obese female. Presentation of anemia, low albumin, elevated LFT at 8th month despite good intake. Rapid course of weight loss after BS and/or long bypassed limb could be responsible. Bowel length measurement is recommended to avoid a short common intestinal channel ${ }^{(8)}$.

Patients after laparoscopic mini-gastric bypass surgery should increase the ingestion of high-protein drinks or food, alcoholic drinks and exercise, to prevent a low hemoglobin level ${ }^{(\mathbf{9})}$.

Great advancements made in the development of bariatric surgical techniques have resulted in new techniques such as the single anastomosis sleeve ileal bypass (SASI) procedure, which emerged as a novel metabolic and bariatric surgery based on Santoro's operation, in which sleeve gastrectomy is followed by gastroileal loop anastomosis ${ }^{(\mathbf{1 0 )}}$.

Such a procedure maintains the normal pathway of food, allowing only a small percentage of ingested food to be absorbed, while the majority of food is bypassed directly into the ileum and induces the metabolic effect of the procedure ${ }^{(10)}$.

In addition, it has the advantages of being associated with minimal postoperative nutritional complications and allows the complete visualization of biliary system using endoscopy ${ }^{(11)}$.

In addition, the gastro-ileostomy anastomosis was made in dependent part of the area between antrum and body of the stomach which imparts greater safety in comparison to other techniques due to its minimal tension and minimal incidence of leakage or serious morbidity ${ }^{(11)}$.

Single anastomosis sleeve ileal bypass has emerged as anew and easy to perform surgical technique that can overcome some of therefore mentioned limitations, most importantly malabsorption, as it does not rely on the omission of any part of the digestive system and therefore does not interfere with important digestive functions ${ }^{(\mathbf{1 0})}$.

However, there are certain downsides to these surgical techniques, which can cause malabsorption and diarrhea, and consequently 
can result in the loss of important nutrients such as calcium, iron, and folic acid.

\section{AIM OF THE WORK:}

The aim of our study is to compare preliminary outcomes between single anastmosis sleeve ileal bypass and mini-gastric bypass at one year, as regards to their effects on hemoglobin, albumin, calcium and Folate.

\section{PATIENTS AND METHODS:}

\section{* Study design}

A prospective comparative study was conducted in Eldmerdash Hospital and El Sahel Teaching Hospital including 60 patients who will undergo bariatric surgery. Patients will be divided into two groups: either (group I) or (group II). The two groups had the same indications for surgery. Group (1) including thirty cases managed by single anastomosis sleeve ileal bypass and group (2) including thirty cases managed by Mini gastric bypass.

\section{* Type of the study :}

Prospective Randomized Controlled Trial

\section{* Inclusion Criteria:}

- Patients of age 18-50 years

- BMI $>35 \mathrm{~kg} / \mathrm{m} 2$

- Either sex

- ASA physical status II \& III

- Undergoing laparoscopic surgery.

* Exclusion criteria:

- Uncompensated cardiovascular disease (e.g. uncontrolled hypertension, atrio-ventricular block, sinus bradycardia, congenital heart disease, reduced LV compliance, diastolic dysfunction)

- Hepato-renal insufficiency

- Uncontrolled endocrinology disease (e.g. diabetes mellitus, hypothyroidism)

- Pulmonary dysfunction (obstructive/ restrictive lung disease)

- Acute/chronic drug dependence/substance abuse

- Requirement of postoperative ventilation
- Refusal to informed consent

All patients included in the study will be candidates for:

\section{Clinical assessment:}

- Detailed medical and family history

- Full Clinical examination including.

\section{Investigation:}

- Routine laboratory investigations $(\mathrm{CBC}$, coagulation profile, liver functions, kidney functions, RBS)

- Calcium, albumin, folate.

- ECG.

- Pelvi-abdominal u/s - X-ray chest.

\section{Preoperatively:}

- Patients will be fully informed about the Risks and Benefits of the Procedures.

4. Informed Consent will be obtained from every Patient.

\section{Intraoperative:}

\section{* Single anastomosis sleeve ileal bypass technique:}

Patients were intubated in a supine position and pneumoperitoneum was established through a $10-\mathrm{mm}$ umbilical visiport. One $5-\mathrm{mm}$ trocar was placed under xiphoid process for the insertion of liver retractor and 12- and $15-\mathrm{mm}$ trocars were placed on the right and left-middle clavicular lines, respectively, for surgeon instruments. Another 5-mm trocar was placed on the left anterior auxiliary line for assistance.

Oral Ryle's tube was inserted to deflate the stomach, and dissection started on the greater curve $5 \mathrm{~cm}$ from the pylorus up to the cardioesophageal junction until full mobilization of the gastric fundus was achieved. After liberating the stomach from great curvature, a 38-French orogastric tube was inserted into the stomach and the duodenum. The stomach was then resected using linear staplers that were applied parallel to the lesser curve starting 3 to $5 \mathrm{~cm}$ from the pylorus up to the angle of Hiss. Hemostasis and staple line were checked using methylene blue (Figure 1). After creation of the sleeved gastric tube, the patient's position was changed to trendelenburg position. The transverse mesocolon was retracted toward the head of the patient and $250 \mathrm{~cm}$ of small 


\section{Alaa Abbaas Moustafa, et al.,}

intestine was measured from ileocecal junction. Then an antecolic side-toside gastro-jejunstomy at the posterior wall of the area between antrum and the body of the stomach was performed with 45$\mathrm{mm}$ linear stapler (Figures 2). The stapler gastroentrotomy was closed with a Vicryl 2/0 continuous stitch (Figure 3). A naso-gastric tube

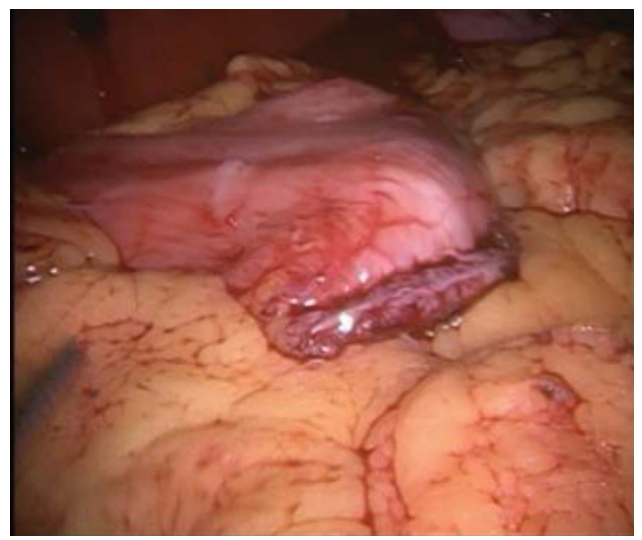

Figure (2): Sleeve gasterectomy is the first sten for SASI.

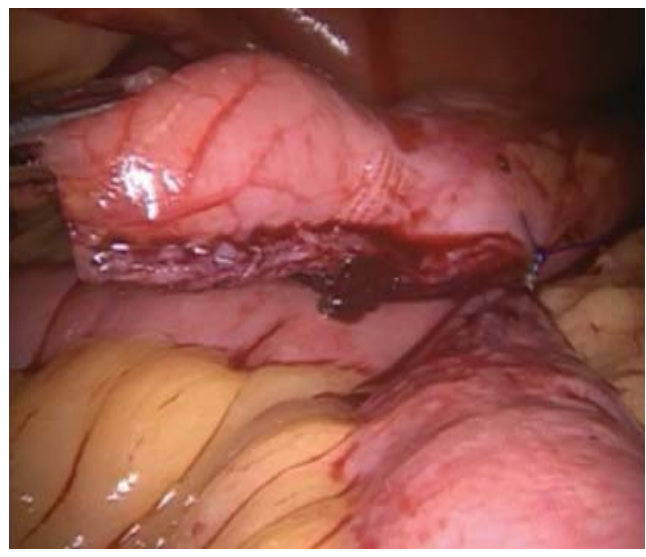

Figure (4): Gastrojujnosytomy is done in the posterior wall of the stomach just lateral to the antrum.

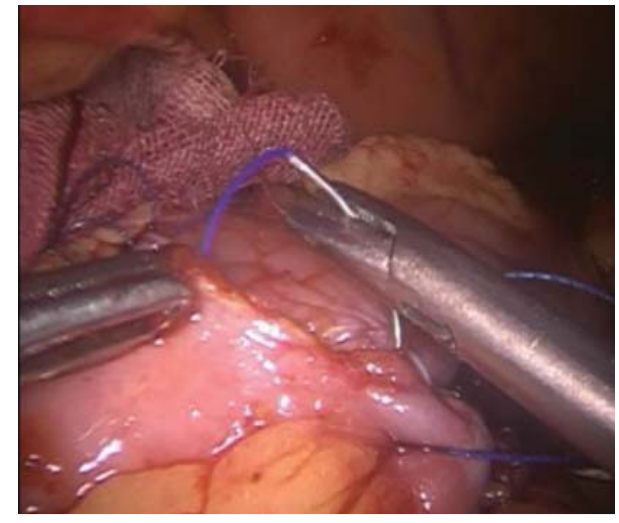

Figure (5): Closure of gastrojujnostomy opening using $2 / 0$ prolene. was placed in the gastric pouch and the leak test was performed by injecting $50-100 \mathrm{cc}$ of methylene blue, and the resected stomach was then removed through the left mid-clavicular port. The procedure ended with a gastric tube having two outlets: one to the duodenum and another to the ileum (Figures 4 and 5). Drains were left for $24 \mathrm{hr}$.

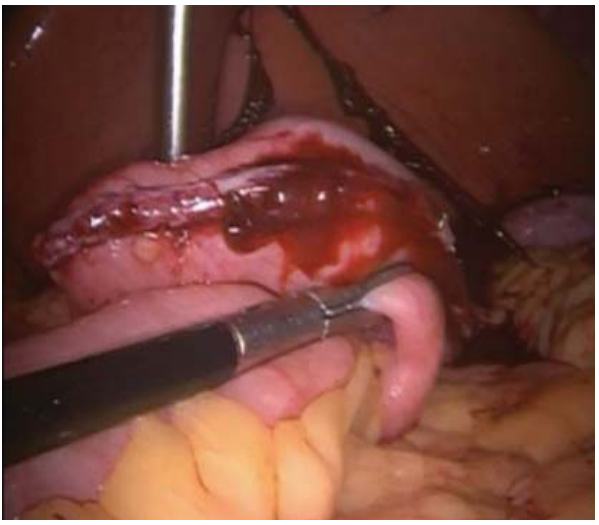

Figure (1): Gastrojesnostmy anastomosis was done $300 \mathrm{~cm}$ from ileocecal valve.

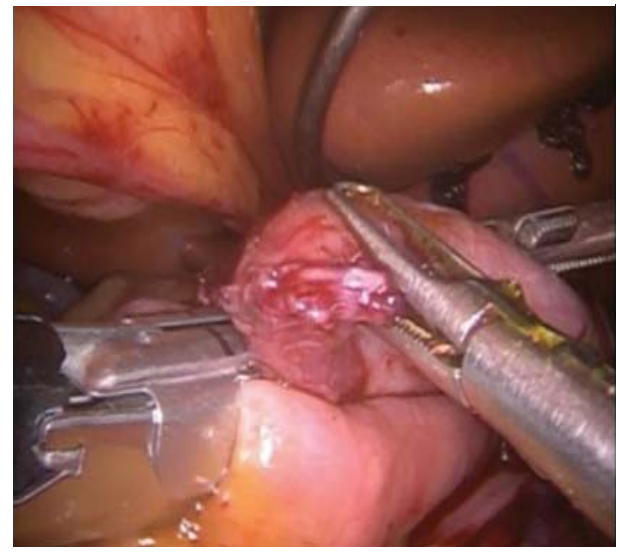

Figure (3): Performing gastrojujnostomy using $45 \mathrm{~mm}$ linear stapler.

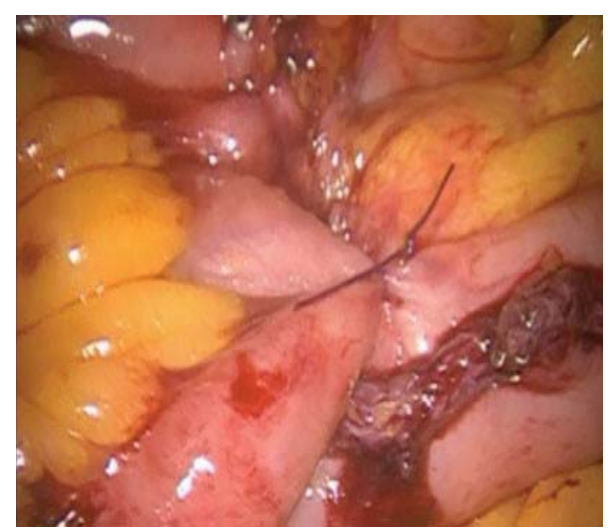

Figure (6): End result of the operation sleeve gastrectomy with two outlet (SASI). 


\section{* Mini gastric bypass technique:}

The operation is performed with the patient in the supine position with legs open and with 45 degrees inclined position. The attachment of the patient to the surgical table is made by placing two belts (on the abdominal area and below the level of the thighs, respectively). The surgeon stands between the legs. Urinary bladder catheterization is not used. Antibiotic prophylaxis were routinely administered. A disposable orogastric tube (Fouchet 32-Fr) is routinely placed.

The pneumoperitoneum is performed by means of a direct puncture with a Veress needle in the left upper quadrant, near the costal margin at the level of the midclavicular line (Palmer's point). The initial pressure is set at $15 \mathrm{mmHg}$, and maintained till the expected pressure (about 15 $\mathrm{mmHg}$ ) is reached. The surgery initiates by the placement of the $10 \mathrm{~mm}$ permanent trocars for introduction of 30 degrees optics/camera placed at the mesogastrium between $12-15 \mathrm{~cm}$ below the xiphoid process and $3 \mathrm{~cm}$ to the left of the midline, considered as number 1 trocar. The trocar number 2 , of $5 \mathrm{~mm}$, is placed near the xiphoid process for the use of liver retractor which is usually a stick/probe held by the $2^{\text {nd }}$ assistant. The number 3 , disposable of $12 \mathrm{~mm}$, is used by the surgeon's left hand, placed on the right side of the patient in an intermediate position between the previous two, 3$5 \mathrm{~cm}$ lateral to the midline. The number 4 , also permanent of $5 \mathrm{~mm}$, is placed along the left costal margin in the anterior axillary line to the $1^{\text {st }}$ assistant. The last trocar, number 5 , disposable of $12 \mathrm{~mm}$, is placed adjacent to the left costal margin in the hemi-clavicular line to surgeon's right hand manipulation. The pneumoperitoneum is maintained by trocar number 5 .

The operation begins with the dissection of the esophagogastric angle and the opening of the left gastrophrenic ligament with a harmonic scalpel, so as to expose the lateral aspect of the left diaphragmatic crus. Then, the ressection of the fat pad of the esophagogastric junction (Belsey's fat) is performed. Then, the surgeon proceeds the ligation of the distal lesser sac, next to the insertion of the Latarjet nerve, using a harmonic scalpel until the exposure of the posterior gastric wall. The gastric pouch must be lengthy and narrow, measuring around $15-18 \mathrm{~cm}$, with a $50-150 \mathrm{ml}$ reservoir capacity. The pouch is created using 01 unit of $45 \mathrm{~mm}$ blue cartridges to perform the horizontal section and 02 to 03 units to perform the vertical section. The stapling lines of the pouch and excluded stomach are then reinforced with a 3-0 polydioxanone continuous suture.

The Treitz ligament is then identified and the small bowel is counted until $200 \mathrm{~cm}$ from the Treitz angle, determining the exclusion of part of the stomach, duodenum, and proximal jejunum from the food pathway. This segment is then attached to the pouch and a vertical or slightly oblique omega-loop, antecolic, and side-to-side $25 \mathrm{~mm}$-gastrojejunostomy is performed using a 60 $\mathrm{mm}$ blue cartilage; the orifice for the cartilage insertion is closed by means of a contonius suture with 3-0 polydioxanone with separate stitches of 30 polyester. The placement of a ring around the gastric pouch is randomly opted following the study protocol for evalution of the effects of the ring. The randomization is performed by means of an electronic device and the individuals are notified of the result of the randomization process prior to the surgery. Among the individuals which have a $6.5-\mathrm{cm}$ silicone ring placed, it is attached to the pouch with 3-0 polypropylene stitches.

\section{Postoperatively:}

- Broad spectrum antibiotics and PPI.

- Surgical site drain will be placed intraoperatively and will be kept for one day.

- Hospital stay: from 24 to 48 hours.

\section{RESULTS}

A prospective comparative study was conducted in Eldermdash Hospital and El Sahel Teaching Hospital including 60 patients who underwent bariatric surgery. Patients were divided into two groups: either (group I) or (group II). The two groups had the same indications for surgery. Group (1) included thirty cases managed by single anastomosis sleeve ileal bypass and group (2) included thirty cases managed by Mini gastric bypass.

\section{Statistical analysis}

- Collected data were compiled and analyzed using SPSS version 23 (SPSS Inc., Chicago, IL) with statistical significance established at $\mathrm{p} \leq 0.05$.

- Continuous variables are presented as means ( \pm standard deviation [SD]), and categorical variables were presented using 


\section{Alaa Abbaas Moustafa, et al.,}

relative frequency distributions and percentages.

- Categorical data were analyzed using the chi-square test, or Fisher's exact test.

- Continuous variables were compared using independent t-test

Statistical significance established at $\mathrm{p} \leq 0.05$.

Table (1): Shows the baseline demographic characteristics of both groups.

\begin{tabular}{|l|c|c|c|}
\hline & $\begin{array}{c}\text { Group 1 } \\
(\mathrm{n}=30)\end{array}$ & $\begin{array}{c}\text { Group 2 } \\
(\mathrm{n}=30)\end{array}$ & P-value \\
\hline $\begin{array}{l}\text { Gender } \\
\text { Female }\end{array}$ & $\begin{array}{c}27(90 \%) \\
3(10 \%)\end{array}$ & $\begin{array}{c}28(93.3 \%) \\
2(6.7 \%)\end{array}$ & $0.002 *^{1}$ \\
\hline $\begin{array}{l}\text { Age } \\
\text { Male }\end{array}$ & $40.34(3.07)$ & $39.51(4.12)$ & $0.871^{2}$ \\
\hline BMI Mean (SD) & $39.18(1.24)$ & $45.04(0.92)$ & $0.001^{2}$ \\
\hline
\end{tabular}

1. Fisher exact test used;

2. Independent $t$ test used.

*Statistically significant difference $(\mathrm{p}<0.05)$.

Both study groups were comparable at baseline in age and gender (Table 1). Women were the majority of patients in both operation groups.

The mean pre-operative BMI was significantly higher in group 2 compared to group1.

Table (2): Nutritional parameters at baseline and after one month follow-up among both groups.

\begin{tabular}{|c|c|c|c|c|}
\hline Variable & Groups & Baseline & 1 month & P-value \\
\hline $\mathrm{BMI}_{[\mathrm{kg} / \mathrm{m} 2]}$ & $\begin{array}{l}\text { Group 1 } \\
\text { Group } 2 \\
\text { P-value }\end{array}$ & $\begin{array}{c}39.18(1.24) \\
45.04(0.92) \\
0.001 *^{2}\end{array}$ & $\begin{array}{c}35.81(0.82) \\
41.01(1.13) \\
0.001 *^{2}\end{array}$ & $0.002{ }^{* 1}$ \\
\hline $\mathrm{EWL}_{[\%]}$ & $\begin{array}{l}\text { Group 1 } \\
\text { Group 2 } \\
\text { P-value }\end{array}$ & & $\begin{array}{l}24.64 \\
21.18 \\
0.062^{2}\end{array}$ & \\
\hline Hemoglobin $_{[\mathrm{g} / \mathrm{dL}]}$ & $\begin{array}{l}\text { Group 1 } \\
\text { Group 2 } \\
\text { P-value }\end{array}$ & $\begin{array}{c}14.1(0.62) \\
13.8(1.14) \\
0.152^{2}\end{array}$ & $\begin{array}{c}13.2(0.73) \\
13.1(0.64) \\
0.428^{2}\end{array}$ & $\begin{array}{l}0.047^{* 1}, \\
0.037^{* 1}\end{array}$ \\
\hline Albumin $_{[\mathrm{g} / \mathrm{L}]}$ & $\begin{array}{l}\text { Group 1 } \\
\text { Group } 2 \\
\text { P-value }\end{array}$ & $\begin{array}{c}39.7(1.54) \\
40.2(1.04) \\
0.108^{2}\end{array}$ & $\begin{array}{c}38.2(0.74) \\
37.8(1.25) \\
0.112^{2}\end{array}$ & $\begin{array}{l}0.117^{1} \\
0.109^{1}\end{array}$ \\
\hline Calcium $_{[\mathrm{mmol} / \mathrm{L}]}$ & $\begin{array}{l}\text { Group 1 } \\
\text { Group } 2 \\
\text { P-value }\end{array}$ & $\begin{array}{c}2.32(0.41) \\
2.31(0.02) \\
0.872^{2}\end{array}$ & $\begin{array}{c}2.30(0.54) \\
2.29(1.13) \\
0.872^{2}\end{array}$ & $\begin{array}{c}0.002^{* 1} \\
0.719^{1}\end{array}$ \\
\hline Folic acid $[\mathrm{nmol} / \mathrm{L}]$ & $\begin{array}{l}\text { Group 1 } \\
\text { Group 2 } \\
\text { P-value }\end{array}$ & $\begin{array}{c}19.7(2.08) \\
18.8(2.12) \\
0.154^{2}\end{array}$ & $\begin{array}{c}18.1(2.13) \\
18.0(1.83) \\
0.371^{2}\end{array}$ & $\begin{array}{l}0.321^{1} \\
0.725^{1}\end{array}$ \\
\hline
\end{tabular}

BMI, body mass index; \%EWL, \% excess weight loss;

1. Independent t test used. 2. Paired t test used.

*Statistically significant difference $(p<0.05)$.

A significant BMI reduction was observed in both groups at the first month. The mean BMI values were significantly lower in the group 1 compared to group 2 during the follow-up, but the differences in \%EWL were not significant (Table 2). At 1 month postoperatively, there was no significant difference between groups in haemoglobin, albumin, calcium and folic acid levels. Meanwhile haemoglobin, albumin, calcium and folic acid levels decreased within both groups with significant differences in hemoglobin and calcium levels. 
Comparative Study Between Single Anastomosis Sleeve Ileal Bypass And Minigastric Bypass and..

Table 3: Nutritional parameters at baseline and after 6 months follow-up among both groups.

\begin{tabular}{|l|l|c|c|c|}
\hline \multicolumn{1}{|c|}{ Variable } & Groups & Baseline & 6 months & P-value \\
\hline BMI $_{[\mathrm{kg} / \mathrm{m} 2]}$ & Group 1 & $39.18(1.24)$ & $30.16(0.52)$ & $<0.001^{* 1}$ \\
& Group 2 & $45.04(0.92)$ & $31.23(1.09)$ & $<0.00 *^{* 1}$ \\
& P-value & $0.00 *^{2}$ & $0.02 *^{2}$ & \\
\hline EWL $_{[\%]}$ & Group 1 & & 44.23 & \\
& Group 2 & & 41.42 & \\
& P-value & & $0.052^{2}$ & \\
\hline Hemoglobin $_{[\mathrm{g} / \mathrm{dL}]}$ & Group 1 & $14.1(0.62)$ & $12.8(0.64)$ & $0.024^{* 1}$ \\
& Group 2 & $13.8(1.14)$ & $12.7(0.68)$ & $0.021^{* 1}$ \\
& P-value & $0.152^{2}$ & $0.752^{2}$ & \\
\hline Albumin $_{[\mathrm{g} / \mathrm{L}]}$ & Group 1 & $39.7(1.54)$ & $37.1(0.91)$ & $<0.001^{* 1}$ \\
& Group 2 & $40.2(1.04)$ & $36.8(1.08)$ & $<0.001^{* 1}$ \\
& P-value & $0.108^{2}$ & $0.092^{2}$ & \\
\hline Calcium $_{[\mathrm{mmol} / \mathrm{L}]}$ & Group 1 & $2.32(0.41)$ & $2.29(0.49)$ & $<0.001^{* 1}$ \\
& Group 2 & $2.31(0.02)$ & $2.28(1.0)$ & $<0.001^{* 1}$ \\
& P-value & $0.872^{2}$ & $0.814^{2}$ & \\
\hline Folic acid \\
& Group 1 & $19.7(2.08)$ & $17.2(2.13)$ & $0.073^{1}$ \\
& Group 2 & $18.8(2.12)$ & $17.1(1.83)$ & $0.080^{1}$ \\
& P-value & $0.154^{2}$ & $0.712^{2}$ & \\
\hline
\end{tabular}

BMI, body mass index; \%EWL, \% excess weight loss;

1. Independent $t$ test used. 2. Paired t test used.

*Statistically significant difference ( $\mathrm{p}<0.05$ ).p1 (baseline vs. 1 month), p2 (baseline vs. 12 month).

A significant BMI reduction was observed in albumin, calcium and folic acid levels. Meanwhile both groups after 6 months among both groups. The mean BMI values were significantly lower in the group 1 compared to group 2 (Table 3 ). After 6 months postoperatively, there was no significant difference between groups in haemoglobin, haemoglobin, albumin, calcium and folic acid levels decreased within both groups with significant differences in hemoglobin, albumin and calcium levels.

Table 4: Nutritional parameters at baseline and after 12 months follow-up among both groups.

\begin{tabular}{|l|l|c|c|c|}
\hline \multicolumn{1}{|c|}{ Variable } & Groups & Baseline & 12 months & P-value \\
\hline BMI $_{[\mathrm{kg} / \mathrm{m} 2]}$ & Group 1 & $39.18(1.24)$ & $28.71(1.24)$ & $<0.001^{* 1}$ \\
& Group 2 & $45.04(0.92)$ & $30.12(1.92)$ & $<0.001^{* 1}$ \\
& P-value & $0.00 *^{2}$ & $0.034^{2}$ & \\
\hline EWL $_{[\%]}$ & Group 1 & & 67.16 & \\
& Group 2 & & 61.82 & \\
& P-value & & $0.054^{2}$ & \\
\hline Hemoglobin $_{[\mathrm{g} / \mathrm{dL}]}$ & Group 1 & $14.1(0.62)$ & $12.5(1.04)$ & $0.031^{* 1}$ \\
& Group 2 & $13.8(1.14)$ & $12.4(0.95)$ & $0.030^{* 1}$ \\
& P-value & $0.152^{2}$ & $0.247^{2}$ & \\
\hline Albumin \\
& Group 1 & $39.7(1.54)$ & $36.1(1.15)$ & $<0.001^{* 1}$ \\
& Group 2 & $40.2(1.04)$ & $35.9(1.02)$ & $<0.001^{* 1}$ \\
& P-value & $0.108^{2}$ & $0.067^{2}$ & \\
\hline Calcium \\
& Group 1 & $2.32(0.41)$ & $2.28(0.61)$ & $<0.001^{* 1}$ \\
& Group 2 & $2.31(0.02)$ & $2.27(0.31)$ & $0.042^{* 1}$ \\
& P-value & $0.872^{2}$ & $0.872^{2}$ & \\
\hline Folic acid ${ }_{[\mathrm{nmol} / \mathrm{L}]}$ & Group 1 & $19.7(2.08)$ & $16.4(1.24)$ & $0.088^{1}$ \\
& Group 2 & $18.8(2.12)$ & $16.2(1.87)$ & $0.328^{1}$ \\
& P-value & $0.154^{2}$ & $0.276^{2}$ & \\
\hline
\end{tabular}

BMI, body mass index; \%EWL, \% excess weight loss;

1. Independent t test used. 2. Paired t test used.

*Statistically significant difference $(p<0.05)$. 
A significant BMI reduction was observed in both groups after 12 months among both groups. The mean BMI values were significantly lower in the group 1 compared to group 2 during the follow-up (Table 4). After 12 months postoperatively, there was no significant difference between groups in haemoglobin, albumin, calcium and folic acid levels. Meanwhile haemoglobin, albumin, calcium and folic acid levels decreased within both groups with significant differences in hemoglobin, albumin and calcium levels.

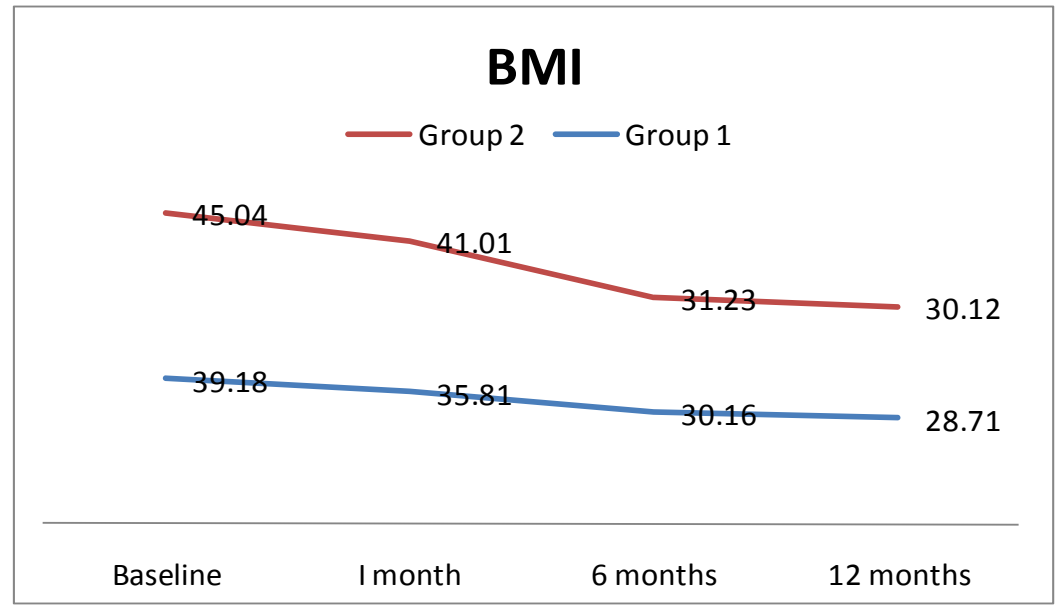

Figure (7): BMI among both groups during follow-up

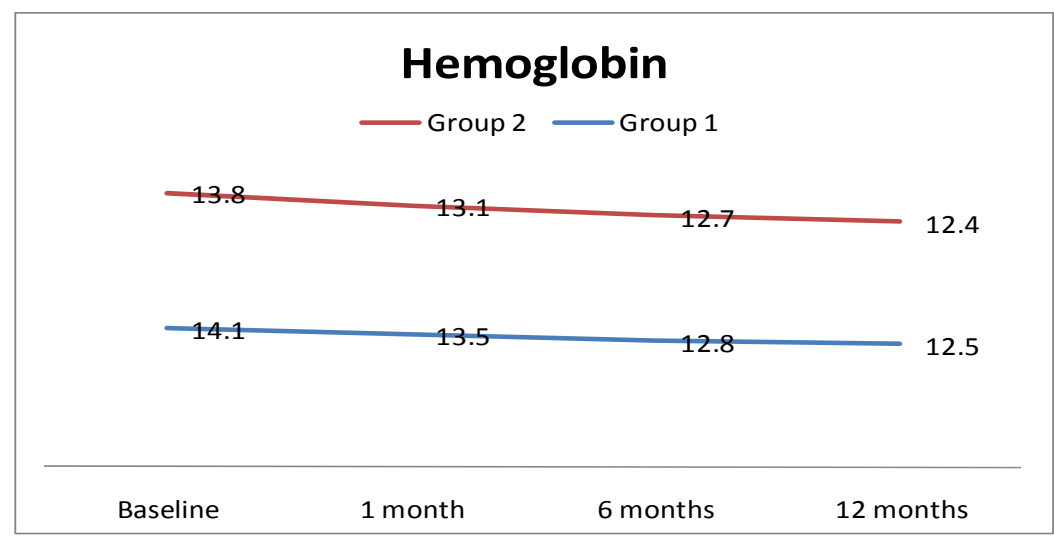

Figure (8): Hemoglobin levels among both groups during follow-up

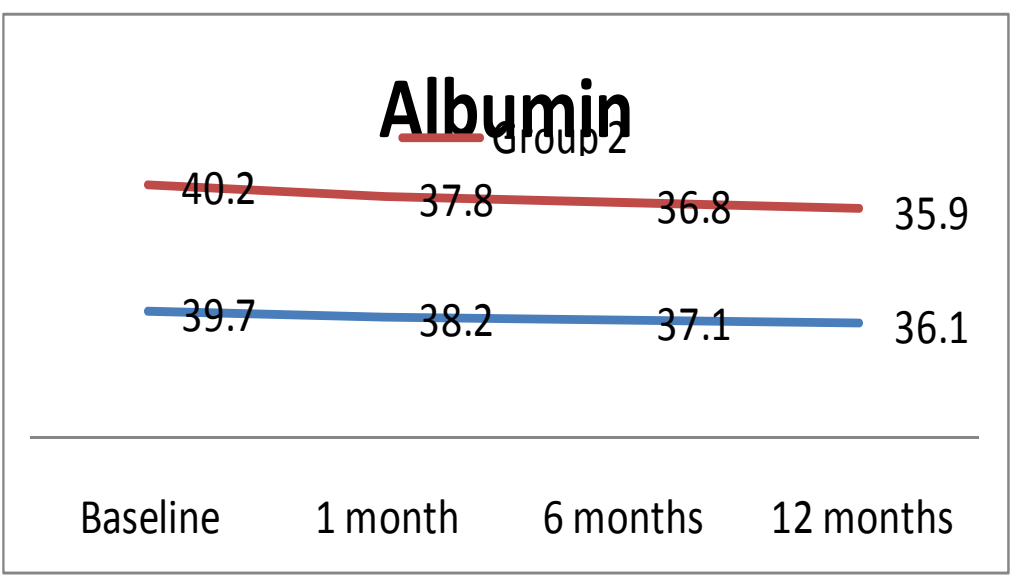

Figure (9): Albumin levels among both groups during follow-up 


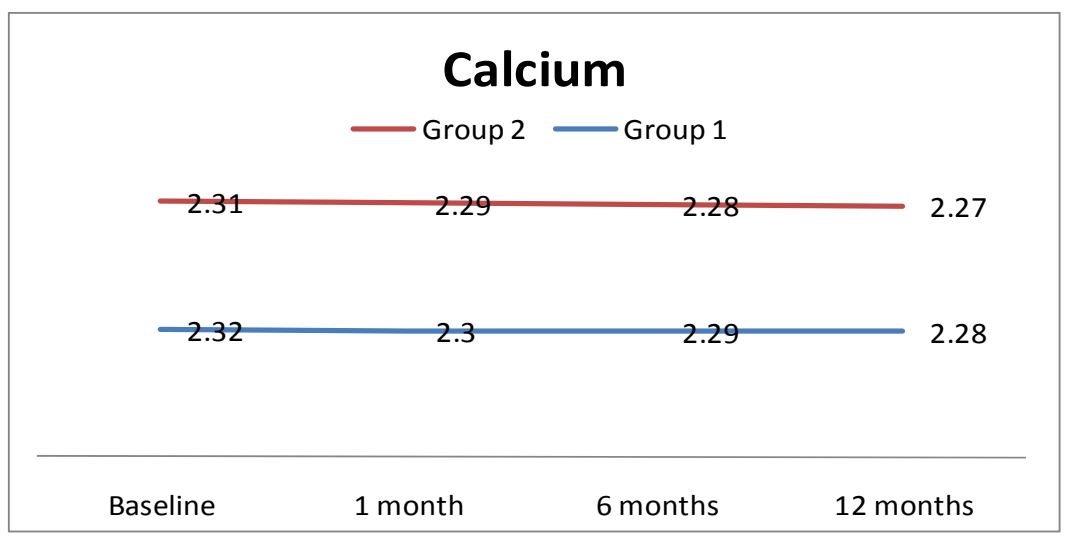

Figure (10): Calcium levels among both groups during follow-up

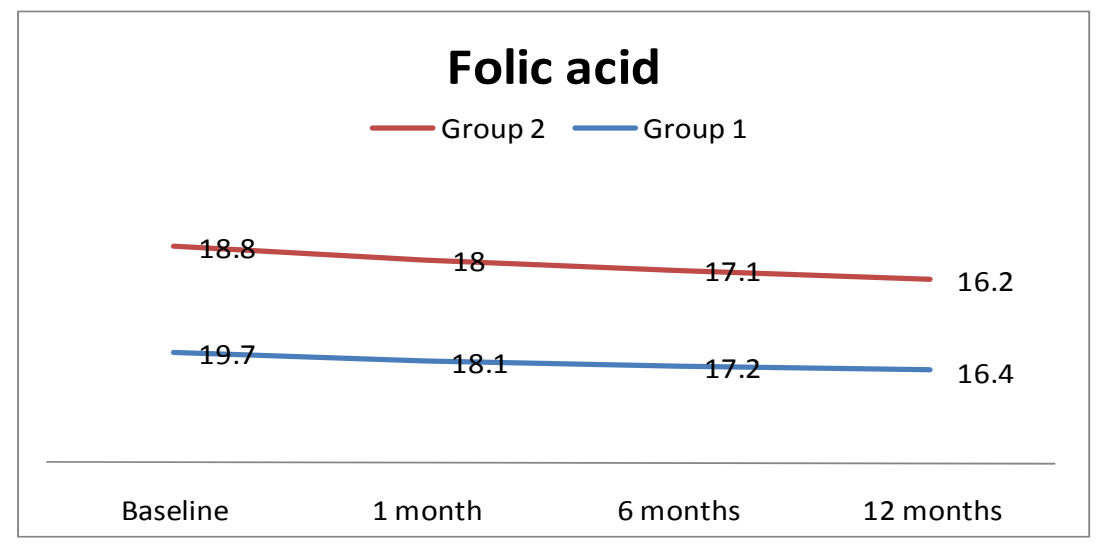

Figure (11): Folic acid levels among both groups during follow-up

\section{DISCUSSION:}

Over the past few decades, many studies have reported that there has been an increased incidence in obesity. With no signs of slowing down, this incidence has reached epidemic levels in USA and other countries around the globe. According to a representative sample of nearly 14,000 individuals in the National Health and Nutrition Examination Survey. The prevalence of obesity among adults in the USA, defined as body mass index $(\mathrm{BMI}) \geq 30 \mathrm{~kg} / \mathrm{m}^{2}$ [calculated as weight (kilograms) divided by the square of the height (meter)] increased from 13\% in 1962 to $32 \%$ in 2004 . With $3 \%$ of men and $7 \%$ of women classified as being severely obese $\left(\mathrm{BMI} \geq 40 \mathrm{~kg} / \mathrm{m}^{2}\right)$ in the most recent estimate. ${ }^{(12)}$

Disproportionate increase in the prevalence of super obesity $\left(B M I \geq 50 \mathrm{~kg} / \mathrm{m}^{2}\right)$ is evident when specifically examining trends in severe obesity, with a nearly tenfold increase in the prevalence of super obesity between 1986 and 2005 , as compared to a twofold increase in obesity (BMI $\geq 30 \mathrm{~kg} / \mathrm{m}^{2}$ ) and fivefold increase in severe obesity $\left(\mathrm{BMI} \geq 40 \mathrm{~kg} / \mathrm{m}^{2}\right)$ during this period. ${ }^{(13)}$

Obesity represents the most serious health problem in 21th century. Besides, it is one of the most important preventable causes of death according to multiple reports. Multiple diseases have been linked to obesity including type II diabetes (T2D), hypertension, coronary heart disease, dyslipidemia, metabolic syndrome $\mathrm{X}$, some forms of cancer, osteoarthritis, and psychosocial problems. ${ }^{(14)}$

Multiple medical and surgical ways have been proposed to treat obesity. Medical methods include exercise, diet, as well as some medications like phentermine and more recently combination drugs containing phentermine and topiramate. Nevertheless, these options achieve modest weight loss and are difficult to sustain over the long term. Conversely, bariatric surgery can achieve sustained and more effective weight 


\section{Alaa Abbaas Moustafa, et al.,}

loss. In addition, it leads to resolution of many obesity related comorbidities. ${ }^{(15)}$

As it achieves better short- and long-term results, bariatric surgical procedures are considered the best current treatment option for severe obesity. Being a modification of the biliopancreatic diversion procedure originally described by Scopinaro, duodenal switch (DS) is a bariatric procedure that depends mainly on malabsorption. The main differences between the two procedures are preservation of the pylorus, sleeve gastrectomy (SG) to reduce the gastric reservoir, and a common channel with a length of $100 \mathrm{~cm}$ rather than $50 \mathrm{~cm}$ as described originally by Scopinaro. ${ }^{(16)}$

Food absorption is decreased by the diversion of biliopancreatic secretions in this procedure. In addition, rapid delivery of nutrients into the terminal ileum stimulates the secretion of many hormones that play an important role in obesity improvement. ${ }^{(17)}$

The RYGB generally is one of the bestestablished procedures in bariatric surgery. Nevertheless, the failure rate with weight regain due to a dilatation of the gastric pouch, gastrojejunostomy and proximal jejunum is up to $35 \%$. Recently, bile reflux was identified as one important cause of postoperative pain. Again, a postpyloric reconstruction seems tempting for this procedure. ${ }^{(18)}$

Laparoscopic mini gastric bypass (MGB) (omega gastric bypass (OGB)) is newer bariatric procedures. MGB has been reported to be a very safe, simple, and effective bariatric procedure. All the reports published to date have been very encouraging. ${ }^{(19)}$

Various studies of the MGB have reported excellent results with the additional benefits of being relatively simple to perform and associated with low complication rates .The MGB was designed to overcome limitations of the RYGB and improve its outcomes. The goal was to create a powerful operation that was simple with minimal complications, a short learning curve, a high degree of efficacy, and that was easily reversed or revised. ${ }^{(20)}$

The main objective of our study was to compare preliminary outcomes between single anastomosis sleeve ileal bypass and mini-gastric bypass at one year, as regards to their effects on hemoglobin, albumin, calcium and Folate.
A Prospective Randomized Controlled Trial was conducted in Eldermdash Hospital and El Sahel Teaching Hospital including 60 patients who would undergo bariatric surgery. Patients were divided into two groups: either (group I) or (group II). The two groups had the same indications for surgery. Group (1) including thirty cases managed by single anastomosis sleeve ileal bypass and group (2) including thirty cases managed by Mini gastric bypass. The duration of the study ranges from 6 to 12 months.

\section{The main results of the study were as following:}

Women were the majority of patients in both operation groups. The mean pre-operative BMI was significantly higher in group 2 compared to group1. The mean of age in group 1 was 40.34 years and the mean of age in group 2 was 39.51 years.

Our results are supported by study of Mahdy et al. $^{(21)}$ as they reported that three hundred ninety patients were female (70.8\%) and 161 (29.2\%) were male. The mean age of the patients was 39.1 \pm 14.7 (range, 18-60) years. The mean preoperative BMI was $43.2 \pm 12.5$ (range, $35-80$ ) $\mathrm{kg} / \mathrm{m} 2$.

According to Abd-Elatif et al. ${ }^{(22)}$, the study included 37 morbidly obese patients who underwent open SADI-S. Females, 31(83.8\%) patients, comprised the majority of cases while $6(16.2 \%)$ were males.

Gasteyger et al. ${ }^{(23)}$ observed that age at surgery was $39.9 \pm 10.0$ y (range: $19-64 \mathrm{y}$ ), and BMI was $46.7 \pm 6.5$ (range: $38.0-69.7$ ).

Furthermore, Jammu \& Sharma ${ }^{(24)}$ revealed there were 295 (26.5\%) RYGB cases of which $210(71.2 \%)$ were female and 85 (28.8 $\%)$ were male, with mean age of 38 and mean BMI of 42.5. There were 473 MGB cases of which $333(70.4 \%)$ were female and 140 (29.6 $\%$ ) were male, with mean age of 46.5 and mean BMI of 56.5 (range 40-73).

Magouliotis and his associates compared the effects of mini-gastric bypass to Roux-en-Y procedure. The mean BMI of the included patients for MGB was $43.8 \mathrm{~kg} / \mathrm{m} 2$ (18). ${ }^{(25)}$

However, Elsayed et al. ${ }^{(26)}$ found that the mean age of the included patients was 34.76 and 
36.0 years for DS and MGB groups respectively. In each group, 20 females $(80 \%)$ as well as 5 males $(20 \%)$ were included. The mean BMI of the included patients was 52.59 and $51.6 \mathrm{~kg} / \mathrm{m} 2$ for both groups respectively.

The present study shows that A significant BMI reduction was observed in both groups at the first month. The mean BMI values were significantly lower in the group 1 compared to group 2 during the follow-up, but the differences in $\%$ EWL were not significant. At 1 month postoperatively, there was no significant difference between groups in haemoglobin, albumin, calcium and folic acid levels. Meanwhile haemoglobin, albumin, calcium and folic acid levels decreased within both groups with significant differences in hemoglobin and calcium levels.

There was a significant BMI reduction was observed in both groups after 6 months among both groups. The mean BMI values were significantly lower in the group 1 compared to group 2. After 6 months postoperatively, there was no significant difference between groups in haemoglobin, albumin, calcium and folic acid levels. Meanwhile haemoglobin, albumin, calcium and folic acid levels decreased within both groups with significant differences in hemoglobin, albumin and calcium levels.

Our results are supported by study of Elsayed et al. ${ }^{(26)}$, as they reported that mean patient weight decreased postoperatively to $128.92,117.63$, and $105.28 \mathrm{~kg}$ after 3,6 , and 12 months in DS group. In the MGB group, mean weight decreased to $133.75,124.14,117.16 \mathrm{~kg}$ at the same time intervals respectively. BMI decreased to $48.45,43.01$, and $38.27 \mathrm{~kg} / \mathrm{m} 2$ in DS group while in the other group it showed a decrease down to $49.35,46.89$, and $42.33 \mathrm{~kg} / \mathrm{m} 2$ at the previously reported time intervals in order of speech. It was evident that 6- and 12-month changes were significantly better in Ds group compared to MGB group ( $\mathrm{p}<0.05$ ). No significant difference was detected between the two groups regarding preoperative albumin, lipid profile, or HbA1c levels.

Another study conducted by Moon et al. ${ }^{\text {(27) }}$ has reported that percentage of excess weight loss was 38.5 and $62.4 \%$ after 6 and 12 months after DS respectively. Moreover, percentage of excess body mass index loss was 41.9 and
$68.1 \%$ at the same time intervals. Furthermore, total percentage of weight loss was reported to be 23.1 and $37.1 \%$ respectively.

Bhandari and his colleagues reported that percentage total weight loss was 28.75 and $33.03 \%$ after 6 and 12 months respectively following MGB surgery. Besides, percentage excess weight loss was 65.23 and $74.88 \%$ at the same time intervals respectively ${ }^{(28)}$.

Furthermore, Jammu \& Sharma ${ }^{(24)}$ found that in all cases of MGB where the length of bypass was $200 \mathrm{~cm}$, no hypoalbuminemia resulted except in one case with diabetic nephropathy. Severe hypoalbuminemia was maximum in the MGB group, seen in longer bypasses, i.e., $>250 \mathrm{~cm}$ (done in our early experience, often for super-obesity), which caused increased protein malabsorption. With RYGB, DeFilipp et al. ${ }^{(29)}$ found that longer bypasses led to more macronutrient deficiency.

The current study shows that a significant BMI reduction was observed in both groups after 12 months among both groups. The mean BMI values were significantly lower in the group 1 compared to group 2 during the follow-up. After 12 months postoperatively, there was no significant difference between groups in haemoglobin, albumin, calcium and folic acid levels. Meanwhile haemoglobin, albumin, calcium and folic acid levels decreased within both groups with significant differences in hemoglobin, albumin and calcium levels.

Our results are supported by study of Mahdy et al. ${ }^{(21)}$ as they reported that a significant decrease in the BMI was observed $(43.2 \pm 12.5$ to $31.2 \pm 9.7 \mathrm{~kg} / \mathrm{m} 2 ; \mathrm{p}<0.0001)$. The $\%$ EWL at 12 months after the SASI bypass was approximately $64 \%$. This was higher than the average \%EWL after sleeve gastrectomy $(56 \%)$ but less than the average \%EWL after RYGB (68\%) in the study conducted by Fischer et al. ${ }^{(30)}$. However, the first study conducted by Mahdy et al. ${ }^{(31)}$ on the efficacy of the SASI bypass reported a much higher \%EWL at 12 months postoperatively, reaching up to $90 \%$. This discrepancy may be explained by the different levels of experience of the operating surgeons. This study included several centers and different surgeons with varying level of experience with the procedure. 
The occurrence of anemia after RYGB and MGB is attributed to malabsorption. Maximum absorption of iron occurs in the duodenal and proximal jejunum, which are bypassed in MGB and RYGB. Also, the lack of $\mathrm{HCl}$ in the stomach contributes to less iron absorption. A higher incidence of anemia was seen in menstruating women. Nutritional deficiencies can be prevented by the surveillance of the multidisciplinary team ${ }^{(32)}$. If oral iron supplementation (Proferrin ${ }^{\circledR}$ t.i.d., iron heme peptide) fails, IV therapy is required. Blood transfusion is rarely required (23) ${ }^{(33)}$. In Jammu \& Sharma ${ }^{(16)}$ series, blood transfusion was required in one case of RYGB and three cases of MGB.

Furthermore, van der Beek et al. ${ }^{(34)}$ reported that post-operative, a significant increase in the number of patients with anemia and deficiencies of ferritin and vitamin B12 was found. Most deficiencies occur between 12 and 15 months post-operatively, but vitamin D3 deficiency occurs significantly earlier at 9.7 months. A preoperative iron, folic acid or ferritin deficiency results in a significant higher risk for developing a post-operative deficiency despite supplementation, and ferritin deficiency occurs significantly earlier in these patients. Oral treatment of post-operative vitamin $\mathrm{B} 12$ and vitamin D3 deficiencies was successful in more than $80 \%$ of the patients in contrast to oral treatment of anemia which was only successful in $62.5 \%$ of the patients.

The preliminary data of a study by Aarts et $a l .{ }^{(35)}$ show a substantial decline in postoperative ferritin and vitamin B12 deficiency in patients taking a supplement containing a high dose of vitamin B12 and iron $(14,000 \%$ and 500 $\%$ of the daily recommended dietary allowance, respectively). An increase in the daily intake of vitamin $\mathrm{D}$ did not result in less deficiencies. These results suggest an insufficiency of present-day standard supplementation, but further study on the effectiveness and risks of high dose supplementation is warranted.

There are some limitations to our study. The low number of patients undergoing surgery in our institution limited the power of statistical comparisons in our study. Furthermore, the follow up of the patients included short and medium term only. As a result, more studies including larger number of patients with longer follow up periods should be conducted in the future.

\section{Conclusion:}

Nutritional deficiencies commonly occur in morbidly obese patients undergoing gastric bypass surgery. The first step in prevention of postoperative deficiencies is preoperative assessment and treatment of nutritional deficiencies in all patients. The preoperative nutritional status is indicative for the incidence and time of onset of post-operative deficiencies which can contribute to optimal nutritional follow-up. Standard supplementation decreases the incidence of postoperative deficiencies.

\section{REFERENCES:}

2. Velhote, M.C.P., \& Damiani, D. (2010). Bariatric surgery in adolescents: preliminary 1-year results with a novel technique (Santoro III). Obesity surgery 20(12): 1710-1715.

3. Buchwald, H., Avidor, Y., Braunwald, E., Jensen, M. D., Pories, W., Fahrbach, K., \& Schoelles, K. (2004). Bariatric surgery: a systematic review and metaanalysis. Jama, 292(14), 1724-1737.

4. Fujioka, K. (2005). Follow-up of nutritional and metabolic problems after bariatric surgery. Diabetes care, 28(2), 481-484.

5. Richardson, W. S., Plaisance, A. M., Periou, L., Buquoi, J., \& Tillery, D. (2009). Long-term Management of Patients after Weight Loss Surgery. The Ochsner Journal; 9(3), 154-159.

6. Chauhan, V., Vaid, M., Gupta, M., Kalanuria, A., \& Parashar, A. (2010). Metabolic, renal, and nutritional consequences of bariatric surgery: implications for the clinician. Southern medical journal, 103(8), 775-83.

7. Kansou, G., Lechaux, D., Delarue, J., Badic, B., Le Gall, M., Guillerm, \& Thereaux, J. (2016). Laparoscopic sleeve gastrectomy versus laparoscopic mini gastric bypass: One year outcomes. International Journal of Surgery, 33, 1822. 
8. Rutledge R. (2001).The Mini-Gastric Bypass: Experience with the First 1,274 Cases. Obesity Surgery; 11(3): 276-280.

9. Motamedi MAK, Rakhshani N, Khalaj A, et al. (2017). Biopsy-proven progressive fatty liver disease nine months post mini-gastric bypass surgery: A case study. International Journal of Surgery Case Reports; 39: 168171.

10. Chen, M. C., Lee, Y. C., Lee, W. J., Liu, H. L., \& Ser, K. H. (2012). Diet behavior and low hemoglobin level after laparoscopic mini-gastric bypass surgery. Hepatogastroenterology, 59(120), 2530-2532.

11. Tarek M, Abdel Wahid W, Carl S. (2015). Laparoscopic single anastmosis sleeve ileumbypass (SASI bypass): technique and preliminary results. SurgObes. Relat Dis; 11: 56-211.

12. Santoro S, Klajner S, Sampaio R. (2015). Sleeve gastrectomy and transit bipartition. Obes Diabetes; 3: 89-110.

13. Prachand V.N., DaVee R.T., \& Alverdy J.C. (2006). Duodenal switch provides superior weight loss in the superobese (BMI $\geq$ $50 \mathrm{~kg} / \mathrm{m} 2$ ) compared with gastric bypass. Annals of surgery, 244 (4), 611.

14. Sturm R. (2007). Increases in morbid obesity in the USA: 2000-2005. Public health, 121 (7), 492-496.

15. Williams E.P., Mesidor M., Winters K., Dubbert P.M., \&Wyatt S.B. (2015). Overweight and obesity: prevalence, consequences, and causes of a growing public health problem. Current obesity reports, 4 (3), 363-370.

16. DeMaria E.J., Pate V., Warthen M., \&Winegar D.A. (2010). Baseline data from American society for metabolic and bariatric surgery-designated bariatric surgery centers of excellence using the bariatric outcomes longitudinal database. Surgery for Obesity and Related Diseases, 6 (4), 347-355.

17. Jатmu G.S. \& Sharma R. (2016). A 7-year clinical audit of 1107 patients comparing sleeve gastrectomy, Roux-En-Y gastric bypass, and mini-gastric bypass, to determine an effective and safe bariatric and metabolic procedure. Obesity surgery, 26 (5), 926-932.
18. Rubino, F., \& Marescaux, J. (2004). Effect of duodenal-jejunal exclusion in a non-obese animal model of type 2 diabetes: a new perspective for an old disease. Annals of surgery, 239 (1): 1.

19. Padwal R., Klarenbach S., Wiebe N., Birch D., Karmali S., Manns B., Hazel M., Sharma A., and Tonelli M. (2011). Bariatric surgery: a systematic review and network metaanalysis of randomized trials. Obesity Reviews, 12 (8), 602-621.

20. Mahawar, K. K., Jennings, N., Brown, J., Gupta, A., Balupuri, S., \& Small, P. K. (2013). Minil gastric bypass: systematic review of a controversial procedure. Obesity surgery, 23 (11), 1890-1898.

21. Rutledge, R., Kular, K. S., Marchanda, N., Bandari, M., \& Goel, R. (2014). A comparison of the outcomes of revision of the Roux-en-Y (RNY) and mini-gastric bypass $(M G B)$; hard vs. easy. Eur $J$ Endosc Laparosc Surg, 1, 1-6.

22. Mahdy, T., Emile, S. H., Madyan, A., Schou, C., Alwahidi, A., Ribeiro, R., \& Shikora, S. (2019). Evaluation of the Efficacy of Single Anastomosis Sleeve Ileal (SASI) Bypass for Patients with Morbid Obesity: a Multicenter Study. Obesity surgery, 1-9.

23. Abd-Elatif, A., Youssef, T., Farid, M., Ali, Y., \& Gado, W. (2015). Nutritional markers after loop duodenal switch (SADI-S) for morbid obesity: a technique with favorable nutritional outcome. $J$ Obes Weight Loss Ther, 5(3), 1000268.

24. Gasteyger, C., Suter, M., Gaillard, R. C., \& Giusti, V. (2008). Nutritional deficiencies after Roux-en-Y gastric bypass for morbid obesity often cannot be prevented by standard multivitamin supplementation. The American journal of clinical nutrition, 87(5), 11281133.

25. Jammu, G. S., \& Sharma, R. (2016). A 7-year clinical audit of 1107 cases comparing sleeve gastrectomy, Roux-En-Y gastric bypass, and mini-gastric bypass, to determine an effective and safe bariatric and metabolic procedure. Obesity surgery, 26(5), 926-932.

26. Magouliotis, D. E., Tasiopoulou, V. S., \& Tzovaras, G. (2018). One anastomosis gastric bypass versus Roux-en-Y gastric bypass for 


\section{Alaa Abbaas Moustafa, et al.,}

morbid obesity: a meta - analysis. Clinical obesity, 8(3), 159-169.

27. Elsayed Y.A, Atif Mohamed Abd El -Latif, Tamer Youssef Mohamed, Hesham Mohamed Abdalla and Mohamed khidr Mohamed. (2019). Comparative study between sleeve gastrectomy with single anastomosis duodeno-ileal bypass and mini-gastric bypass in management of morbid obesity. Int. J. Adv. Res. 7(10), 72-83.

28. Moon R.C., Gaskins L., Teixeira A.F., \& Jawad M.A. (2018). Safety and effectiveness of single-anastomosis duodenal switch procedure: 2-year result from a single US institution. Obesity surgery, 28 (6), 15711577.

29. Bhandari, M., Nautiyal, H. K., Kosta, S., Mathur, W., \& Fobi, M. (2019). Comparison of one-anastomosis gastric bypass and Rouxen-Y gastric bypass for treatment of obesity: a 5-year study. Surgery for Obesity and Related Diseases, 15(12), 2038-2044.

30. DeFilipp, Z., Lister, J., Gagné, D., Shadduck, R. K., Prendergast, L., \& Kennedy, M. (2013). Intravenous iron replacement for persistent iron deficiency anemia after Roux-en-Y gastric bypass. Surgery for Obesity and Related Diseases, 9(1), 129-132.

31. Fischer, L., Hildebrandt, C., Bruckner, T., Kenngott, H., Linke, G. R., Gehrig, T., \& Müller-Stich, B. P. (2012). Excessive weight loss after sleeve gastrectomy: a systematic review. Obesity surgery, 22(5), 721-731

32. Mahdy T, Al Wahedi A, Schou C. (2016). Efficacy of single anastomosis sleeve ileal (SASI) bypass for type-2 diabetic morbid obese patients: Gastric bipartition, a novel metabolic surgery procedure: A retrospective cohort study. Int J Surg.;34:28-34.

33. Dolan, K., Hatzifotis, M., Newbury, L., Lowe, N., \& Fielding, G. (2004). A clinical and nutritional comparison of biliopancreatic diversion with and without duodenal switch. Annals of surgery, 240(1), 51.

34. Marceau, P., Biron, S., Hould, F. S., Lebel, S., Marceau, S., Lescelleur, O., \& Simard, S. (2007). Duodenal switch: long-term results. Obesity surgery, 17(11), 1421-1430.

35. van der Beek, E. S., Monpellier, V. M., Eland, I., Tromp, E., \& van Ramshorst, B. (2015). Nutritional deficiencies in gastric bypass patients; incidence, time of occurrence and implications for post-operative surveillance. Obesity surgery, 25(5), 818-823.

36. Aarts, DE., Betzel, B., Koehestanie, P., Ploeger, N., Van Laarhoven, C., \& Berends, F. (2013). A double-blind prospective randomized controlled trial comparing multivitamin supplements after roux-en-Y gastric bypass in morbidly obese patients: vital study. On IFSO, $18^{\text {th }}$ cong. $2^{\text {nd }}$ session. 
دارسة مقارنة بين عملية التكميم الساسي مع تحويل مسار الاثنى عشر وعملية تحويل المسار المصغز وتأثيرها على الهيموجلوبين والالبيومين والكالسيوم وحمض الفوليك

علاء عباس مصطفى وتامر محمد سعيد ومحمد جمال الفولي ومصطفى سعد عبدالسلام قسم الجراحة العامة، كلية الطب- جامعة عين شمس

الخلفية: تعد جراحات إنقاص الوزن أكثر الطرق نجاحاً لمعالجة السمنة المفرطة والتي عن طريقها يتم تحقيق الوزن المثالي وتثبيته لقتزة زمنية طويلة. ومثل هذه الجراحات هو تصغير حجم المعدة او تحويل المسار او الاثثين معا، مما حققت افضل النتائج للحصول على الوزن المثالي. الهرف: مقارنة بين عطلية التكبيم الساسي مع تحويل مسار الاثثى عثر وعملية تحويل المسار الدصغر وتأثيرها على الهيموجلوبين والالبيومين والكالسيوم وحضض الفوليك.

7. المرضى والطرق: هذه دراسة مقارنة مستقبلية أجريت في مستثفى الامرداش ومستشفى الساحل التعليمي بما في ذلك مريضاً سيخضعون لجراحة لعلاج البدانة. سيتم تقسيم المرضى إلى مجموعتني: إما (المجموعة الأولى) أو (المجموعة الثانية). النتائج: وقد لوحظ انخفاض كبير في مؤشر كتلة الجسم في كلا المجموعتين في 1، 7 و Y شهرا من المتابعة. كانت قيم

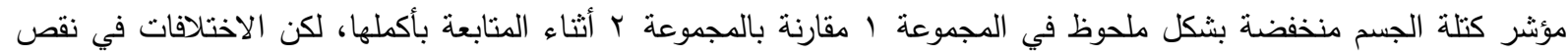
الوزن المتوقع لم تكن كبيرة. لا يوجد اختلاف بين المجموعتين فى نقص الهموجلبين والكالسيوم والألبومين وحصض الفوليك ولكن يوجد نقص مقارنة بقبل العطلية.

الخلاصة: تحدث حالات نقص التغذية بشكل شائع في المرضى الذين يعانون من السمنة المفرطة والذين يخضعون لعملية

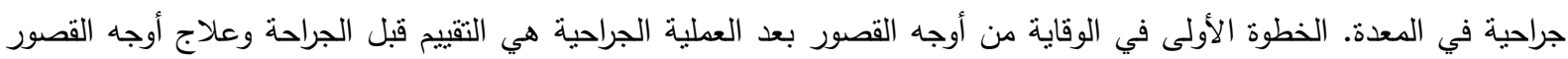

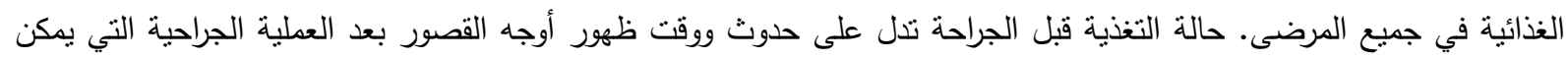
أن تسهم في متابعة التغذية المثلى. مكملات القياسية يقلل من حالات القصور بعد العملية الجراحية. 